\title{
Estimating Information Rigidity using Firms' Survey Data
}

\author{
César Carrera* \\ * Banco Central de Reserva del Perú
}

\author{
DT. N²012-004 \\ Serie de Documentos de Trabajo \\ Working Paper series \\ Enero 2012
}

Los puntos de vista expresados en este documento de trabajo corresponden al autor y no reflejan necesariamente la posición del Banco Central de Reserva del Perú. 


\title{
Estimating Information Rigidity using Firms' Survey Data
}

\author{
CÉSAR CARrera ${ }^{\dagger}$ \\ Banco Central de Reserva del Perú
}

January 2012

\begin{abstract}
:
The slope of the sticky information Phillips curve proposed by Mankiw and Reis (2002) is based on the degree of information rigidity on the part of firms. Carroll (2003) uses an epidemiology model of expectations and finds evidence for the U.S. of a one-year lag in the transmission of information from professional forecasters to households. Using financial institutions' and firms' survey data from Peru and the model proposed by Carroll, I estimate the degree of information rigidity for the Peruvian economy. This paper also considers heterogeneous responses and explores the cross-sectional dimension of these survey forecasts. I find that the degree of information stickiness is such that it takes between one and three quarters for updating information, a result that is robust to different specifications.
\end{abstract}

\section{JEL Classification: D84, E31, C11, C53, C82}

Key words: Inflation expectations, Heterogeneous expectations, Survey expectations, Epidemiology, Sticky Information.

\footnotetext{
${ }^{\dagger}$ I would like to thank Carl Walsh, James Hamilton, Thomas Wu, Yuriy Gorodnichenko, Andrea Ferrero, Carlos Dobkin, Aspen Gorry, George Alessandria, and Abel Rodriguez for valuable comments and suggestions. I would like to thank the participants of the III PHD Econ Seminar at UC Santa Cruz and of the XXIX Encuentro de Economistas sponsored by the Central Bank of Peru. The points of view expressed throughout this document are the author's own and are not necessarily shared by the institutions with which he is currently affiliated.

CÉSAR CARrera is a Senior Economist in the Research Department, Banco Central de Reserva del Perú, Jr. Miroquesada 441, Lima, Perú. Email: cesar.carrera@bcrp.gob.pe
} 


\section{INTRODUCTION}

During the past ten years, several papers have argued that sticky information models, in which agents update their information occasionally rather than instantaneously, explain some stylized facts about output and inflation dynamics. This research aims at estimating the slope of the Phillips curve, which in turn describes the relationship between inflation, economic activity, and expectations. Having the correct structural parameters allows a better understanding of the dynamics of inflation, for example, in response to monetary policy shocks.

Mankiw and Reis (2002, MR thereafter) pioneered the literature on sticky information modeling. Their work was motivated by the following stylized facts about inflation dynamics: (i) monetary policy actions require some time to have their full impact on inflation, (ii) there is a large and positive serial correlation in the inflation process, (iii) disinflation policies have contractionary effects, and (iv) monetary policy actions have their maximum effect on cyclical output before they have their maximum effect on inflation. MR proposed a structural explanation for these stylized facts based on information rigidities. ${ }^{1}$

The first attempt to provide microfoundations to MR's (2002) model was Carroll (2003) and his epidemiological model of expectations. Carroll argues that the U.S. survey data on inflation expectations is consistent with a model in which each period only a fraction of households adopt the superior inflation forecasts of experts. The experts' forecast is superior in the sense that they have better available information. The remaining households find it costly to update their information and continue using their own past expectations rather than forming better predictions. In this context, in order to make better predictions, an agent requires more time for analysis and better knowledge of other important information. Reis

\footnotetext{
${ }^{1}$ See Castillo et al. (2006) for stilized facts for Peru.
} 
(2006b) also provides microfoundations for MR (2002) and argues that firms can rationally choose to be inattentive, and he derives the conditions for the optimal length of inattentiveness. MR (2007) conclude that the assumption of sticky information can be justified by the costs of acquiring, absorbing, and processing information (as in Reis, 2006a, 2006b) or by appealing to the epidemiology of expectations (as in Carroll, 2003).

While Carroll's epidemiology model seems to be useful for modeling the U.S. and European data, corresponding work for developing countries is still lacking. While Carroll's model seems to fit the data between professional forecasters and households, corresponding work is still missing between professional forecasters and firms. To the best of my knowledge, there is no available information of firms' expectations. I attempt to fill this gap by investigating inflation expectation data from Peru for both professional forecasters and firm managers.

Regarding expectations, there has been an increasing interest in explaining agents' inflation expectations formation process, ${ }^{2}$ mainly inspired by the evidence against the rational expectations hypothesis provided by survey expectations (Mankiw et al., 2004). Branch (2007) bridges the sticky information and heterogeneous expectations literatures by presenting empirical evidence in favor of both model heterogeneity and limited information flows. Mankiw et al. (2004), Carroll (2003) and Döpke et al. (2008a) find evidence based on survey data supporting sticky information models. Nunes (2009b), instead, obtains empirical evidence against these models, ${ }^{3}$ while Inoue et al. (2009) claim that the correlation between households and professional forecasters' expectations found in Carroll (2003) is higher if the consumption expenditure is considered as a proxy for inflation expectations, ${ }^{4}$ Coibion and Gorodnichenko (2008) find that mean forecasts fail to adjust in response to structural shocks

\footnotetext{
${ }^{2}$ See MR (2006, 2007) and Branch (2007).

${ }^{3}$ Nunes (2009a) proposes a model of expectations based on a rational forecast and on a learning component. That model is then used in Nunes (2009b) and the author argues that this model provides a better fit of the data. ${ }^{4}$ Inoue et al. (2009) claim that households with a lower level of education do not have the incentives to incorporate news into the report of their inflation expectations.
} 
leading to different degrees of informational rigidities, ${ }^{5}$ and Lanne et al. (2009) provide results favoring a simple sticky information model. ${ }^{6}$

Most of the literature focuses on the diffusion of information from professional forecasters to households. However, models based on sticky information assume that information that is relevant to firms' pricing decisions is the information that diffuses slowly in the economy. Therefore, when choosing prices, firms may not immediately update their old information. The firm's decision is rational because of the costs associated with collecting updated information. The specification of inflation dynamics in this context is given by the sticky information Phillips curve (SIPC hereafter) in which current inflation depends not only on the current output gap but also on the past expectations of both current inflation and the growth rate of the current output gap from part of the firm. ${ }^{7}$

My findings support the usefulness of Carroll's modeling strategy for the description of expectation dynamics between professional forecasters and firm managers in Peru. I find that firm managers' inflation expectations adjust slowly relative to the more precise expectations of professional forecasters. This paper presents evidence of information rigidity between these two agents at both the aggregate and the sector levels of economic activity. As a robustness check on my result, I use firm-level data and test different specifications of the model. I argue that the lag in the response of one group with respect to the other group is a valid approximation for the level of information rigidity in the Peruvian economy. Peru is an economy with two high inflation periods (in 1988 and in 1992), a relatively recent independent central bank (in 1992), and an explicit inflation target scheme (since 2002). This

\footnotetext{
${ }^{5}$ Coibion and Gorodnichenko (2010) expand the analysis to explain the "Great Moderation" on expectations and present evidence of state-dependence in the expectation formation process.

${ }^{6}$ Lanne et al. (2009) define simple sticky information as the situation in which a significant proportion of the households base their inflation expectations on the past release of actual inflation rather than on the rational forward-looking forecast. For a recent survey in the past decade on imperfect information models see MR (2010).

${ }^{7}$ Walsh (2010) shows that the conclusions of the sticky information models are sensitive to the slope of the Phillips curve.
} 
study covers a period of relatively low inflation and estimates the transmission of the expectations between two groups of agents: financial institutions that do business based on a better knowledge and understanding of the Peruvian economy and the less informed managers of firms who are the agents who set prices in the economy. ${ }^{8}$

The remaining of this paper is organized as follows: Part 2 introduces the baseline epidemiology model and the basis for information transmission between two groups: financial institutions and firm managers, Part 3 presents the data, methodology, and estimation of the epidemiology model, and finally, Part 4 presents my conclusions.

\section{THEORY}

\subsection{The Carroll Model}

In the Carroll (2003) epidemiology model, information goes from professional forecasters to consumers. The dynamics of expectations are described by a model where households' views depend on news reports about professional forecasters' views. However, households are inattentive because they read news reports only occasionally. This particular feature triggers stickiness in aggregate expectations. Following on Carroll's model, I assume that: (i) most firm managers (FMs hereafter) update their inflation expectations by reading newspaper articles on inflation, (ii) every article contains a complete forecast of the inflation rate for all future years and, (iii) each firm manager (FM hereafter) who read such article absorbs its content with probability $\lambda,{ }^{9}$ then the following holds:

\footnotetext{
${ }^{8}$ See Appendix I for a discussion of inflation, monetary policy, and inflation expectations in Peru.

${ }^{9}$ Additionally, any FM that reads an inflation article can recall the entire forecast and FMs that do not encounter an article continue to believe the last forecast they read.
} 


$$
M_{t}\left[\pi_{t+1}\right]=\lambda N_{t}\left[\pi_{t+1}\right]+(1-\lambda)\left\{\lambda N_{t-1}\left[\pi_{t+1}\right]+(1-\lambda)\left(\lambda N_{t-2}\left[\pi_{t+1}\right]+\cdots\right)\right\}
$$

where $\pi_{t+1}$ is the inflation rate between quarter $t$ and quarter $t+1, p_{t}$ is the aggregate price index in period $t$, then $\pi_{t+1}=\log \left(p_{t+1}\right)-\log \left(p_{t}\right), M_{t}\left[\pi_{t+1}\right]$ is the mean value of inflation expectations of FMs for quarter $t+1$ during the quarter $t$, and $N_{t}\left[\pi_{t+s}\right]$ is the newspaper forecast printed in time $t$ for inflation in $s \geq t$.

In period $t$, a fraction $\lambda$ of the FMs absorbs the current newspaper forecast for the next quarter $N_{t}\left[\pi_{t+s}\right]$. In period $t$, also a fraction $(1-\lambda)$ of the FMs retains the forecasts they held in period $t-1$ for the inflation rate in $t+1$. This is a recursive process of past forecasts of nextperiod inflation.

The assumptions about the inflation process implicit in the FMs' belief are:

- The economy has an underlying "fundamental" inflation rate.

- Future changes in the fundamental rate of inflation are unforecastable.

- The actual inflation rate is equal to that period's fundamental rate plus unforecastable transitory inflation shocks.

From the assumptions above, a FM believes that the inflation process is captured by the following processes:

$$
\begin{aligned}
& \pi_{t}=\pi_{t}^{f}+\varepsilon_{t} \\
& \pi_{t+1}^{f}=\pi_{t}^{f}+\eta_{t+1}
\end{aligned}
$$

where $\varepsilon_{t}$ is a transitory shock to the inflation rate in period $t$ while $\eta_{t}$ is the permanent innovation in the fundamental inflation rate $\pi_{t}^{f}$ in period $t .^{10}$

The following assumptions simplify the model and make it more tractable:

\footnotetext{
${ }^{10}$ The belief of FMs for the values of $\eta$ beyond period $t+1$ and the values of $\varepsilon$ beyond period $t$ is that they are unforecastable white noise variables.
} 
- For periods $t$ and $t+1$, FMs believes that $\varepsilon$ and $\eta$ are directly estimated by professional forecasters.

- Expert forecasters develop some special ability for forecasting inflation (use of private information).

FMs can rationally believe that a forecast from an expert is more accurate than their adaptively rational forecast. These assumptions also imply that rather than containing a forecast for the entire quarter-by-quarter future history of the inflation rate, the newspaper article contains only a forecast of the inflation rate over the next year.

Re-defining $M_{t}$ and $N_{t}$, and define $F_{t}$ for any $s>t$ as follows:

- $\quad \pi_{t, s}$ is the inflation rate between period $t$ and $s$.

- $M_{t}\left[\pi_{t, s}\right]$ is the mean value of inflation expectations for FMs as of date $t$.

- $N_{t}\left[\pi_{t, s}\right]$ is the newspaper forecast (expectation) as of date $t$.

- $F_{t}\left[\pi_{t, s}\right]$ is the FM's forecast (expectation) as of date $t$, for a FM that updates its view from a news report in $t$.

Then, the hypothetical FM's expectation is that the true inflation rate over the next year is given by:

$\pi_{t, t+4}=\pi_{t+1}+\pi_{t+2}+\pi_{t+3}+\pi_{t+4}$

Using (2) and (3):

$\pi_{t, t+4}=4 \pi_{t+1}^{f}+3 \eta_{t+2}+2 \eta_{t+3}+\eta_{t+4}+\varepsilon_{t+1}+\varepsilon_{t+2}+\varepsilon_{t+3}+\varepsilon_{t+4}$

Then, the following holds for FMs' forecasts:

$F_{t}\left[\varepsilon_{t+n}\right]=F_{t}\left[\eta_{t+n+1}\right]$ for $n>0$

Applying (5) to (4):

$F_{t}\left[\pi_{t, t+4}\right]=4 F_{t}\left[\pi_{t+1}^{f}\right]=F_{t}\left[\pi_{t, t+4}^{f}\right]$ 
This result implies that a FM's forecast of the inflation rate is equal to its forecast of the fundamental inflation rate. If FMs believe that the forecasts printed in the newspaper content the inflation process implied in (2), (3), and (4), then:

$$
N_{t}\left[\pi_{t, t+4}\right]=4 N_{t}\left[\pi_{t+1}^{f}\right]=N_{t}\left[\pi_{t, t+4}^{f}\right]
$$

The FM's view about the newspaper forecast is that it contains a projection of the fundamental inflation rate. A FM that reads the newspaper updates its expectations to equal the newspaper forecast:

$$
F_{t}\left[\pi_{t, t+4}\right]=F_{t}\left[\pi_{t, t+4}^{f}\right]=N_{t}\left[\pi_{t, t+4}^{f}\right]=N_{t}\left[\pi_{t, t+4}\right]
$$

When FMs read the newspaper, their views are updated to the forecasts printed in the inflation article. For $n>0$, the newspaper has no information about $\varepsilon_{t+n}$ or $\eta_{t+n+1}$, which give a condition similar to (5):

$$
N_{t}\left[\varepsilon_{t+n}\right]=N_{t}\left[\eta_{t+n+1}\right] \text { for } n>0
$$

The assumption that the changes in inflation rates beyond period $t+1$ are unforecastable implies:

$$
\begin{aligned}
& F_{t-1}\left[\pi_{t-1, t+3}\right]=F_{t-1}\left[\pi_{t, t+4}\right] \\
& F_{t-2}\left[\pi_{t-2, t+2}\right]=F_{t-2}\left[\pi_{t, t+4}\right]
\end{aligned}
$$

An equation similar to (1) can be written for projections of the inflation rate over the next year:

$$
M_{t}\left[\pi_{t, t+4}\right]=\lambda F_{t}\left[\pi_{t, t+4}\right]+(1-\lambda)\left\{\lambda F_{t-1}\left[\pi_{t-1, t+3}\right]+(1-\lambda)\left(\lambda F_{t-2}\left[\pi_{t-2, t+2}\right]+\cdots\right)\right\}
$$

Taking into account the interactive term, replacing $F_{t}$ with $N_{t}$, and assuming that the newspaper forecast is the only source of updating information:

$$
\begin{aligned}
M_{t}\left[\pi_{t, t+4}\right] & =\lambda F_{t}\left[\pi_{t, t+4}\right]+(1-\lambda) M_{t-1}\left[\pi_{t, t+4}\right] \\
M_{t}\left[\pi_{t, t+4}\right] & =\lambda N_{t}\left[\pi_{t, t+4}\right]+(1-\lambda) M_{t-1}\left[\pi_{t-1, t+3}\right]
\end{aligned}
$$


For FMs, their inflation expectations mean should be a weighted average between their current rational forecast and their last period's inflation expectations mean. Because making informed inflation forecasts is costly, FMs do not update their expectations instantaneously but occasionally. Similar to the original Carroll's model with households, new information that appears every period about inflation diffuses from expert forecasters to FMs in the following epidemiological way: a fraction $\lambda$ of FMs updates their inflation expectations to those expert forecasters while the remaining (1- $\lambda)$ fraction of FMs stick to their forecasts made during the previous period.

\section{IDENTIFICATION AND DATA CHARACTERISTICS}

Previous to the estimation of $\lambda$ in this section, I describe first the strategy for approaching the epidemiology model and then present some preliminary results that support this model. In the next section, I use these results for estimating Equation (9).

\subsection{Identification Strategy}

Estimating equation (9) requires an identification of data sources for firms-mean inflation expectations and for newspaper forecasts of inflation over the next year. The Central Reserve Bank of Peru conducts a monthly survey of the general managers of large firms intended to be representative of the Peruvian economy. One component of the survey asks the managers what they expect the inflation rate to be at the end of the year and during the next year. I use the mean inflation forecast from this survey as a proxy for $M_{t}\left[\pi_{t, t+4}\right]$.

For identifying the "newspaper" forecast for next-year inflation, I use the mean next-year inflation forecast from the survey of financial institutions. The survey, also conducted by the Central Reserve Bank of Peru, has collected and summarized forecasts from leading banks, 
pension fund managers, and other financial institutions since 1999. The survey questionnaire is distributed once a month and responses are due within 10 days. The central bank asks participants for monthly and annual forecasts of inflation for the end of the year and the next year.

Typically, a newspaper article on inflation includes interviews from "experts" on inflation, who in turn provide the reasoning behind their predictions. In this case, experts are those professionals who forecast the economy for a living (implying that professionals being interviewed by the media are the same forecasters). Those forecasts are, in turn, summarized by the survey to financial institutions. ${ }^{11}$ Therefore, the indentification of $N_{t}\left[\pi_{t, t+4}\right]$ with the inflation expectations data from the survey of financial institutions is a reasonable approach.

\subsection{Data Description}

Data about expectations are taken from the Central Reserve Bank of Peru. I use financial institutions' and general managers' expectations on inflation. ${ }^{12}$ The inflation rate is computed as the 12-month growth rate of the Consumer Price Index (CPI).

Figures 1 and 2 show that the distribution of both financial institutions' and FMs' forecasts is symmetric around a central value. Table 1 presents some summary statistics as well and confirms that the mean, median, and mode are similar in value. The difference in these three measures of central tendency is no larger than 0.6 percentage point for all years in the sample.

The cross-sectional dispersion of the FMs' answers is larger than the dispersion of financial institutions' answers during all years. The disagreement or uncertainty about inflation among FMs is larger than the disagreement among financial institutions regarding

\footnotetext{
${ }^{11}$ In the particular case of Peru, each financial institution has an Economic Studies department. This department produces a report that includes the institutions's views on the Economy as a whole and its expected values for key variables, especially at the end of each fiscal quarter. Such reports coincide with the publication of the firm's balance sheet.

${ }^{12}$ For details on the time series 12-months-ahead inflation expectations, see Appendix II.
} 
future inflation. Figure 3 reports the dispersion in the answers of both groups and shows that FMs' responses are more disperse.

In Table 1, it is possible to identify that the level of disagreement increases during periods of relatively high inflation. For example, inflation in 2008 is the maximum level recorded for the sample period of analysis and the standard deviation in the forecasts of inflation for 2009 is almost twice the previous year's dispersion. Similar results hold for the inter-quartile statistics. $^{13}$

In Table 2, Panel A, the correlation coefficient is higher between financial institutions' forecast and the most recent information of core inflation than it is between those forecasts and CPI inflation. In contrast, there is a higher correlation between FMs' expectations and CPI inflation than there is between those forecasts and core inflation. This evidence suggests that professional forecasters have better information than FMs about fundamental inflation (measured as core inflation), which is consistent with Carroll's (2003) model.

Nunes (2009b) argues that households are more accurate at forecasting CPI inflation but not core inflation, contradicting Carroll's results. Nunes uses the mean squared error (MSE) and compares the mean and median in the household survey conducted by the University of Michigan and the Survey of Professional Forecasters conducted by the Federal Reserve Bank of Philadelphia. When using the median, Nunes finds that the MSE between households' forecasts and CPI inflation is lower than those between professional forecasters and CPI inflation. The results reverse when core inflation is considered.

In Table 2, Panel B, I present the same test for both sample groups and both measures of central tendency. The financial institutions are always more accurate in their predictions, except in the case of median-CPI inflation. Mankiw et al. (2004) present an exercise during the transition of the Volcker disinflation on how the distribution of inflation expectations in

\footnotetext{
${ }^{13}$ Another possibility that could explain the greater volatility of forecasts during 2008 is the crisis in the U.S. that affected most agents' expectations about inflation.
} 
households evolves. During the transition, the distribution of the households' responses became approximately bi-modal. This fact would explain the consistency of my results compared to Nunes, because the distribution of inflation expectations in my study is symmetric for the case of Peruvian FMs, which explain why the mean and median would be the same.

\subsection{Granger Causality Test}

Another potential explanation of the financial institutions' inflation expectations is that they observe FMs' expectations first in order to build their own expectations. It is possible to argue that the relationship between managers of FMs and the research department of financial institutions is a channel that would work in both directions.

A way to test the suggested structure of the epidemiology model (expectations spread from financial institutions' research departments to the FMs) is to test that the financial institutions' forecasts should Granger-cause the FMs' forecasts, but not vice versa. In Table 3 I show that there is evidence of Granger causality from the financial institutions' forecasts to FMs' forecast, but no evidence of Granger causality in the opposite direction. In other words, the lags of financial institutions' expectations are typically significant predictors of FMs' expectations but FMs' expectations tend not to Granger-cause financial institutions' expectations. Thus, the direction of Granger causality goes from professional forecasters toward FMs.

\section{ESTIMATIONS AND EMPIRICS}

The news about inflation can be thought of as a disease that spreads slowly across the FMs, infecting a fraction $\lambda$ of all the FMs in each period. Hence Equation (9) is directly estimable, given that an appropriate proxy for newspaper articles on inflation expectations 
can be found and $\lambda$ can be thought as the degree of information rigidity of the expectations of the FMs with respect to the professional forecasters. ${ }^{14}$

\subsection{Degree of Information Stickiness}

I now turn to the main question: Can the FMs' survey data be reasonably well represented by the reduced-form model represented by (9)? As Döpke et al. (2008a) point out, the underlying time-series properties of inflation expectations determine the appropriate empirical approach. In the case of time series that are stationary, OLS is the correct technique for estimating Equation (9) (as in Carroll, 2003). If this is not the case (i.e. non-stationary) and the time series are cointegrated, Equation (9) should be estimated with a vector errorcorrection (VEC) model. ${ }^{15}$

Augmented Dickey-Fuller (ADF) tests suggest that the series of expectations are stationary. For the sample period that this study covers, cointegration techniques are not recommended. So, taking into account the preliminary evidence from previous subsections that support the epidemiological model of expectations, I estimate the speed of information updating, captured by $\lambda$ in Equation (9).

Equation 1 of Table 4 provides a baseline for comparison and presents the result for the simplest possible model: FMs' forecasts, $M_{t}\left[\pi_{t, t+4}\right]$, is equal to a constant, $\alpha_{0}$. The point estimate of the constant is 2.6 percent, which is close to the center of the inflation band $(2.5$ percent) announced by the central bank in 2002-2006. ${ }^{16}$ The parameter is statistically

\footnotetext{
${ }^{14}$ Regarding the estimation of information rigidity, most work about sticky information uses time series analysis. Khan and Zhu (2006), Coibion (2010), Döpke (2008a), and Carrera (2010) use non-linear OLS for estimating the degree of information rigidity. Kiley (2007) employs a maximum likelihood methodology. Kiley (2007) also suggests that in environments of relatively low inflation, the degree of information rigidity tends to increase.

${ }^{15}$ Döpke et al. (2008a) follow Carroll's strategy but do not present any evidence in favor of any order of integration for inflation or inflation expectations. They argue that the objective of their paper is to test the validity of Carroll's epidemiology model and estimate this model using both empirical strategies.

${ }^{16}$ In 2007, the central bank announced a lower inflation targeting ( 2 percent) with the same length of band (1 percent below and over the target).
} 
significant and, as expected, the $\bar{R}^{2}$ is equal to zero. The test performed for the benchmark model is whether the average value of the expectations is zero, $\alpha_{0}=0$. This hypothesis can be rejected with a high degree of statistical confidence (the $\rho$-value indicates that the probability that the hypothesis is true is close to zero).

I evaluate the baseline model's ability to explain the FMs' expectations by estimating an equation of the form:

$$
M_{t}\left[\pi_{t, t+4}\right]=\alpha_{1} S_{t}\left[\pi_{t, t+4}\right]+\alpha_{2} M_{t-1}\left[\pi_{t-1, t+3}\right]+\varepsilon_{t}
$$

where $S_{t}\left[\pi_{t, t+4}\right]$ is the financial institutions' forecast. Equation (10) can be compared with (9) and permits testing the following restriction:

$$
\alpha_{1}+\alpha_{2}=1
$$

Results from the estimation of (10) are presented as Equation 2. The point estimates of $\alpha_{1}=0.46$ and $\alpha_{2}=0.51$ suggest that (11) is very close to holding true. The statistical significance with which the restriction (11) can be rejected is about 0.28. This formal statistical evidence of the restriction indicates that this proposition can be easily accommodated by the data at a level of significance of 0.05 or greater. ${ }^{17}$

The above results can be interpreted as a level of information rigidity of two quarters for the Peruvian economy; in other words, all FMs require half a year in order to update information, on average.

The possibility that FMs update their expectations to the most recent inflation rate rather than to the financial institutions' forecast is another reasonable modification to the baseline model. Since most news on inflation also release the most recent inflation statistics (and since the inflation rate is often in the headline of the news article,) it is possible to argue that it

\footnotetext{
${ }^{17}$ There is no evidence of serial correlation in the residuals as indicated by the Q-stat statistic. This is an impressive result because the individual series have very high degrees of serial correlation. This may suggest that the two variables are co-integrated. The ADF results, on the other hand, suggest that these series are stationary. As part of the agenda of this paper, the use of cointegration techniques would be useful when more data are available.
} 
seems likely for FMs to update their expectations to the most recent released number of inflation than to a forecast of the future inflation rate. As pointed out by Carroll, this result would be in line with a model of adaptive expectations.

If FMs believe that the true inflation process follows on (2) and (3), this adaptive expectations approach is similar to the limited-information rational expectations forecast. The epidemiology model assumes that FMs believe that professional forecasters have the most information regarding the inflation process, so their predictions are more accurate than expectations based on the past history of inflation. Therefore, FMs who update information could still believe that the financial institution forecast is better than the adaptively rational forecast. Another possible alternative is some "learning" process from the FMs; so they may take into account past forecast error in order to make their predictions today.

As suggested in Carroll (2003) and Nunes (2009b) it is possible to encompass specifications that include adaptive and learning processes i.e. estimate the following equation:

$$
M_{t}\left(\pi_{t, t+4}\right)=\alpha_{0}+\alpha_{1} S_{t}\left(\pi_{t, t+4}\right)+\alpha_{2} M_{t-1}\left(\pi_{t-1, t+3}\right)+\alpha_{3} \pi_{t}+\alpha_{4} F E_{t}\left[\pi_{t-4, t}\right]+\varepsilon_{t}
$$

where $\pi_{t}$ represents the most recently published annual inflation rate as of time $t$ and $F E_{t}\left[\pi_{t-4, t}\right]$ is the actual forecast error.

Results from estimating (12) are presented in the next rows of Table 4. The results in Equation 3 rule out the possibility that financial institutions' forecasts are not significant if a constant is added. Equation 4 takes into account the possibility that FMs consider the most recent inflation information rather than the forecasts of professional forecasters. In terms of the model, this may imply a prediction of the fundamental inflation rate. Financial institutions' forecasts of future inflation are still a significant determinant of the FMs' forecasts, while actual inflation remains not significant. Similar results hold if rather than past inflation, the forecast error is considered, as I show in Equation 5. 
From Equation 6, the past inflation rates are statistically significant determinants of the FMs' expected inflation rates only when the lagged value of the FMs' forecast is considered. That is not the case for the forecast error.

The last two rows in Table 4 show that when the financial institutions' predictions are entirely absent, the current inflation rate and the forecast error term have explanatory power for the FMs' forecast of the inflation rate.

In the words of Carroll, it seems fair to say that the simple "sticky expectations" equation (9) does a good job of capturing much of the behavior of the FMs' inflation expectations. In all the specifications estimated, financial institutions' expectations are a significant determinant of the FMs' inflation expectations.

\subsection{Heterogeneous Expectations: Industry Level}

It is also possible that different FMs have different incentives to update information, which in turn affects the FMs' expectations. A first approach would be to differentiate FMs according to the economic activity they perform. A similar approach of dividing the survey sample into sub-samples by potential different content of information can be found in Inoue et al. (2009). ${ }^{18}$

After testing Carroll's model per sector, I find that the data still support the main constraint of the model in Equation (11). On the other hand, as expected, the level of rigidity varies in between sectors. As reported in Table 5, FMs that update faster to the financial institutions' forecast are firms involved in manufacturing processes and natural resources extractive activities. The level of information rigidity consistent with these parameters ranges between one and two quarters. The sectors with the most information rigidity are trade and construction, with a rigidity level in a range of two and three quarters.

\footnotetext{
${ }^{18}$ Inoue et al. (2009) show that household survey responses are more highly correlated with professional inflation forecasts if the household has highly educated consumers. Inoue et al. argue that this fact is consistent with the view that more educated consumers are better able to articulate their expectations.
} 
A first way to approach this result is by testing if firms belonging to one particular sector forecast future inflation incorrectly over time, which may bias the estimator of information rigidity from the time series approach. In Figure 4, I present the average inflation point estimate and the level of information rigidity per sector. Even though there is dispersion in the data, such dispersion is well inside the 95 percent confidence band for the whole sample of firms, which supports my result. However, the dispersion suggests that the cross-sectional variation may give me a more robust estimator.

Then I compare the level of information rigidity with the level of disagreement in FMs that carry out different economic activities. In Figure 5 it is possible to find a negative relationship, suggesting that in sectors in which there are more disagreements, the expected time for updating expectations would be higher.

The last test I propose is to compare the level of information rigidity against a proxy for markup. ${ }^{19}$ Sectors that display a higher markup are also sectors with a longer lag in updating information, as suggested in Figure $6 .^{20}$

Even though there are no large variations in point estimates, disagreements, or markup per industry, all these preliminary tests suggest that the cross-sectional dimension of FMs' responses has to be tested in the context of a panel data analysis. Doing so may correct any potential bias due to the systematic forecast error of some FMs.

\subsection{Heterogeneous Expectations: Firm Level}

In order to rule out any type of consistent over-(under-)predictions on the part of any individual FM (or group of FMs), which in turn bias the results from the time series regression, I estimate a panel of FMs that responded at least 38 percent during the sample

\footnotetext{
${ }^{19}$ I take the proportion between the excess in profits relative to the aggregate value generated per economic activity from the last input-output table for the Peruvian economy as a proxy for the markup on a specific industry.

${ }^{20}$ Manufacturing firms have to compete with imported products, which would explain a higher degree of competition and a lower markup relative to other economic activities.
} 
period. $^{21}$ The strategy is to consider any type of consistent, yet significant pattern in FMs' answers. I estimate different fixed effect specifications to account for those patterns. The work of Lahiri and Liu (2006) and Capistrán and Timmermann (2009) also explore the crossdimension of inflation expectations at the individual forecasting level. ${ }^{22}$

The new baseline specification, which considers the cross-dimension at the FM level, following (9), is:

$$
M_{i t}\left[\pi_{t, t+4}\right]=\alpha_{1} S_{t}\left[\pi_{t, t+4}\right]+\alpha_{2} M_{i t-1}\left[\pi_{t-1, t+3}\right]+\varepsilon_{i t}
$$

where $M_{i t}\left[\pi_{t, t+4}\right]$ is redefined as the forecast of inflation for FM $i$ between $\mathrm{t}$ and $\mathrm{t}+4$.

The results are reported in Table 6. In Equation 1, I consider a panel model with constant coefficients, referring to both intercepts and slopes. This specification assumes that neither firm nor temporal effects are statistically significant. In Equation 2 the panel model has constant slopes but intercepts that differ according to the cross-sectional unit (group firm). This specification considers the case of significant differences among FMs, i.e., allows the intercept to be cross-section specific and in this case differs from firm to firm; however, it may or may not differ over time. The type of fixed effects model in Equation 3 has constant slopes but intercepts that differ according to time. In this case, the model has no significant firm differences but might have autocorrelation owing to time-lagged temporal effects. The residuals of this kind of specification may have autocorrelation. In this case, the variables are homogeneous across the FMs. They could be similar in region or area of focus. For example, technological changes or national policies would lead to group-specific characteristics that

\footnotetext{
${ }^{21}$ This ad hoc cut-off of FMs is intended to evaluate the responses of consistent participants in the survey. As a way to check robustness, I estimate the panel for a higher level of responses and the results remain the same. The fixed effects models frequently have too many cross-sectional units of observations requiring too many dummy variables for their specification. Too many dummy variables may limit the model of a sufficient number of degrees of freedom for adequately statistical tests and be subject to multicollinearity, which increases the standard errors and thereby drains the model even more of statistical power to test parameters.

${ }^{22}$ Even though Lahiri and Liu (2006) and Capistrán and Timmermann (2009) focus on explaining inflation uncertainty, using survey data from the Survey of Professional Forecasters (SPF), they both take into account the cross-sectional variation in their studies. Lahiri and Liu find that the persistence in forecast uncertainty is much lower than what the aggregate time series data would suggest. They use a panel of density forecasts from the SPF. Capistrán and Timmermann show that the conditional variance of inflation, the conditional mean of the inflation rate, and the cross-sectional dispersion in inflation beliefs are positively related at the forecaster level.
} 
may affect temporal changes in the FMs' expectations. Equation 4 is another fixed effects panel model in which the slope coefficients are constant, but the intercept varies over firms as well as over time.

Table 6 shows the results for all of these fixed effect specifications. In all of them the forecasts of financial institutions remain significant, with the expected sign and with values around the time series regression estimation. The point estimates suggest that firms, on average, update their information set to that of the financial institutions between 2 and 3 quarters. Equation 1 in Table 6 shows a point estimate of 0.63 , which suggests a level of information rigidity close to 2 quarters. The data on expectations accommodate reasonably well Carroll's epidemiology model and give a reasonable length of the degree of information rigidity for the Peruvian economy.

\section{Conclusions}

A central topic in macroeconomics is the role of private agents' expectations at both the disaggregate and aggregate levels because a better understanding of those expectations also allows a better understanding of structural relationships in the economy. The recent literature on sticky information indicates an important role for the behavior of expectations, especially those arising from firms. Here, I present Carroll's (2003) epidemiologic model of expectations and estimate the information rigidity between financial institutions and the FMs of firms using data from Peru. In this model, there is information rigidity in the sense that financial institutions devote significant resources to updating information, which in turn affects their expectations, but these new expectations are imperfectly transmitted to the managers of private firms.

Information rigidities lead a group of firms to set prices based on past information. The environment in which a FM operates may affect the timing at which this FM updates its 
information set. Moreover, heterogeneity in the timing may arise at the firm and/or industry level for three reasons: (i) some FMs set prices with the best information available, while others have no incentives to incur additional costs for updating information, which would lead to dispersion at the industry level (level of disagreements), (ii) some FMs face more competition, which lowers the markup and the incentive for managers to be more updated (the markup level), and/or (iii) some FMs may not have incentives to reveal the true value of their expectations on inflation (systematic errors in forecasting). Considering these heterogeneities may give a more robust estimate of the information rigidity in the Peruvian economy.

The data support the restriction suggested by Carroll's epidemiology model and suggest a level of information rigidity of half a year. I find that financial institutions' expectations and past expectations of the FMs are significant determinants of the FMs' expectations, result that is robust to different specifications. At the cross-section level, responses about expectations have symmetric distributions for all years, and the data suggest that at high levels of inflation, the level of the inflation forecast increases as well as the disagreement increases between agents.

With heterogeneous FMs (i.e., FMs that belong to different industries) the epidemiologic model closely matches the data on FMs' expectations, with relatively short deviations from the aggregate parameter of the degree of information rigidity. This model succeeds in part because responses about future rates of inflation are on average close to the prediction of the aggregate level. I also consider the disagreement and the markup at the industry level, in order to be more consistent with the data along a number of dimensions. I find a negative relationship in both cases, which suggests a role for testing the cross-dimension in a panel with fixed effects. The results from different fixed effects panel data specifications confirm the robustness of the results found in the time series analysis. 
This model of transmission and expectations suggests that information frictions matter for understanding certain features of FMs' expectations. Future research should study more closely how agents update information other than inflation. Understanding how financial institutions' expectations evolve relative to rational expectations will also shed light on the evolution of FMs' expectations. Consistent with Easaw and Ghoshray (2006), it would be interesting to test these two groups of agents' expectations with different types of shocks and document those results. Finally, Mankiw and Reis (2007) develop a general equilibrium model based on sticky information that replicates the level of disagreement on the household survey expectations. Estimating the level of disagreements of FMs based on a sticky information general equilibrium model would be the natural next step of this research.

\section{APPENDIX I - HIGH INFLATION AND INSTITUTIONAL CHANGES}

The Peruvian economy suffered a period of hyperinflation during 1988 and 1992, as a result of a combination of heterodox policies and a "low" level of institutions' credibility. In 1988 , there was a spiral of "bad" news followed by a shock on expectations, which resulted in a higher level of prices. In 1992, the high level of inflation was announced and several managed prices were set to free market levels, an action that first induced a period of high inflation, and lower levels of inflation thereafter. The central government announced the independence of the central bank and since then the bank's main objective has been price stability.

Since 2002, the Peruvian economy has experienced different structural changes regarding monetary policy. One of those changes was the announcement of an explicit inflation target of 2.5 percent with a band of 1 percent above and below. ${ }^{23}$ Since 2007 , the target has been 2.0 percent with a band of 1 percent above and below. The other important change was the

\footnotetext{
${ }^{23}$ For previous years, many authors consider the inflation target in the IMF letter of intent from Peru as the implicit announced target band for inflation.
} 
switch from an aggregate monetary target to an interest rate as the operative target. Figure A1, as suggested in Easaw and Ghoshray (2006), shows that the band of the inflation target "anchors" the expectations of the professional forecasters and, as implied in Capistrán and Ramos-Francia (2010), the dispersion of the expectations is reduced. Figure A1 also shows that the response of expectations to movements in inflation outside the band is asymmetric. ${ }^{24}$

Therefore the period 2001-2010 is considered a period of relatively low inflation (with a mean of 2.3 percent), low volatility (a standard deviation of 2.1 ) and with the historical record of deflation on 2001 (see Table A1). Regarding expectations, they are mostly symmetric and unimodal in both financial institutions and managers of firms (see again Figures 1 and 2).

\section{APPENDIX II - 12-MONTH EXPECTATIONS APPROXIMATION}

In the survey given to general managers of firms, there is no question about the 12-month estimate of the inflation rate for firms. For financial institutions, this question has been included in the survey since June 2009. On the other hand, the central bank asks for inflation expectations during the current year and the next year for both samples, consistently over time.

I build a time series for the 12-month expectation of inflation as the geometric average between the current-year forecast and the next-year prediction. ${ }^{25}$ The weight for each year is proportional to the time to be forecasted. For example, the estimation of the 12-months-ahead inflation expected in March is:

$$
E_{\text {March }}\left[\pi^{t /(t+1)}\right]=\left[E_{\text {March }}\left(\pi_{\text {Jan }-D e c}^{t}\right)\right]^{\frac{1}{12} * 9}\left[E_{\text {Marc }}\left(\pi_{\text {Jan }-D e c}^{t+1}\right)\right]^{\frac{1}{12} * 3}
$$

\footnotetext{
${ }^{24}$ When contemporaneous inflation is higher than the target band, expectations for next-year inflation are higher and outside the band. When inflation is inside or below the band, expectations tend to be inside the target band. I discuss this topic further in Section 4.

${ }^{25}$ This approach assumes that the agents do lineal forecasts of inflation; i.e., they estimate the average inflation for the year and then expand to a year time period.
} 
where $E_{\text {March }}\left[\pi^{t /(t+1)}\right]$ is the expected inflation in March at year $t$, from April at year $t$ to March at year $\mathrm{t}+1$ and $E_{\text {Marc } h}=\left[\pi_{\text {Jan-Dec }}^{t}\right]$ is the expected inflation in March at year $t$ for January - December of year t. I use a similar approach for both samples.

\section{REFERENCES}

Branch, W., 2007. Sticky information and model uncertainty in survey data on inflation expectations. Journal of Economic Dynamics \& Control 31, 245 - 276.

Capistrán, C., Ramos-Francia, M., 2010. Does Inflation Targeting Affect the Dispersion of Inflation Expectations? Journal of Money, Credit and Banking 42 (1), 113 - 134.

Capistrán, C., Timmermann, A., 2009. Disagreement and Biases in Inflation Expectations. Journal of Money, Credit and Banking 41 (2-3), 365 - 396.

Carrera, C., 2010. Sticky information Phillips curve: Evidence for OECD countries. Dissertation Essay, University of California, Santa Cruz.

Carroll, C., 2003. Macroeconomic Expectations of Households and Professional Forecasters. Quarterly Journal of Economics 118, 269 - 298.

Castillo, P., Montoro, C., Tuesta, V., 2007. Hechos Estilizados de la Economía Peruana. Revista de Estudios Economicos, Central Reserve Bank of Peru, 33 - 75.

Coibion, O., 2010. Testing the Sticky Information Phillips Curve. Review of Economics and Statistics, 92 (1), 87-101.

Coibion, O., Gorodnichenko, Y., 2010. Information Rigidity and the Expectations Formation Process: A Simple Framework and New Facts. NBER Working Paper No. 16537.

Coibion, O., Gorodnichenko, Y., 2008. What Can Survey Forecasts Tell Us About Informational Rigidities? NBER Working Paper No. 14586.

Döpke, J., Dovern J., Fritsche U., Slacalek J., 2008a. The Dynamics of European Inflation Expectations. The B.E. Journal of Macroeconomics: Vol. 8: Iss. 1 (Topics), Article 12.

Döpke, J., Dovern J., Fritsche U., Slacalek J., 2008b. Sticky Information Phillips Curves: European Evidence. Journal of Money, Credit, and Banking 40 (7), 1513-1520.

Easaw, J., Ghoshray, A., 2006. Agent-Based Learning in 'Islands' with 'Sticky Information': An Explanation for the Persistence of Real Effects. Journal of Money, Credit, and Banking 38 (1), $263-268$. 
Inoue, A., Kilian, L., Burcu-Kiraz, F., 2009. Do Actions Speak Louder Than Words? Household Expectations of Inflation Based on Micro Consumption Data. Journal of Money, Credit and Banking 41 (7), 1331 - 1363.

Khan, H., Zhu, Z., 2006. Estimates of the Sticky-Information Phillips Curve for the United States. Journal of Money, Credit, and Banking 38 (1), 195 - 207.

Kiley, M., 2007. A quantitative comparison of sticky-price and sticky-information models of price setting. Journal of Money, Credit, and Banking 39 (1), $101-125$.

Lahiri, K., Liu, F., 2006. Modelling Multi-Period Inflation Uncertainty using a Panel of Density Forecasts. Journal of Applied Econometrics 21, 1199-1219.

Lanne, M., Luoma, A., Luoto, J., 2009. A naive sticky information model of households' inflation expectations. Journal of Economic Dynamics \& Control 33, 1332 - 1344.

Mankiw, N.G., Reis, R., 2010. Imperfect Information and Aggregate Supply. NBER Working Paper 15773.

Mankiw, N.G., Reis, R., 2007. Sticky Information in General Equilibrium. Journal of the European Economic Association, 5 (2-3), 603 - 613.

Mankiw, N.G., Reis, R., 2006. Pervasive Stickiness. American Economic Review 96 (2), 164 $-169$.

Mankiw, N.G., Reis, R., 2002. Sticky information versus sticky prices: a proposal to replace the New Keynesian Phillips curve. Quarterly Journal of Economics 117 (4), 1295 - 1328.

Mankiw, N.G., Reis, R., Wolfers, J., 2004. Disagreement about Inflation Expectations. In: Gertler, M., Rogoff, K. (Eds.), NBER Macroeconomics Annual 2003, 18, 209 - 270.

Nunes, R., 2009a. Learning the Inflation Target. Macroeconomic Dynamics, 13, 167-188.

Nunes, R., 2009b. On the Epidemiological Microfundations of Sticky Information. Oxford Bulletin of Economics and Statistics 71, 5, $643-657$.

Reis, R., 2006a. Inattentive Consumers. Journal of Monetary Economics 53 (8), 1731 - 1800.

Reis, R., 2006b. Inattentive Producers. Review of Economic Studies 73 (3), 793 - 821.

Walsh, C., 2010. Monetary Theory and Policy. The MIT Press. $3^{\text {rd }}$ Edition. 
Table 1

Inflation Expectations: Summary Statistics

\begin{tabular}{llllllllll}
2001 & 2002 & 2003 & 2004 & 2005 & 2006 & 2007 & 2008 & 2009 & 2010 \\
\hline
\end{tabular}

Financial Institutions

$\begin{array}{lcccccccccc}\text { Mean } & 4,4 & 2,4 & 2,1 & 2,1 & 2,9 & 2,5 & 2,3 & 2,8 & 4,2 & 2,2 \\ \text { Median } & 4,1 & 2,5 & 2,0 & 2,1 & 2,5 & 2,5 & 2,3 & 2,8 & 4,0 & 2,1 \\ \text { Mode } & 4,0 & 2,5 & 2,0 & 2,0 & 2,5 & 2,5 & 2,5 & 3,0 & 4,0 & 2,0 \\ & & & & & & & & & & \\ \text { St. Dev. } & 0,9 & 0,7 & 0,4 & 0,3 & 0,6 & 0,4 & 0,4 & 0,6 & 1,0 & 0,4 \\ \text { Interquartile } & 0,5 & 1,0 & 0,5 & 0,3 & 0,7 & 0,0 & 0,5 & 0,5 & 1,4 & 0,5 \\ \text { Observations } & 24 & 29 & 28 & 28 & 28 & 29 & 27 & 22 & 20 & 22\end{array}$

Firms

Mean

Median

Mode

St. Dev.

Interquartile

Observations

Inflation 1/

CPI

CPI Core

$\begin{array}{rr}-0,13 & 1,52 \\ 1,30 & 1,23\end{array}$

2,48

0,73

$\begin{array}{lllllllll}2,7 & 2,6 & 2,6 & 3,2 & 2,1 & 1,9 & 2,1 & 4,6 & 2,4 \\ 2,5 & 2,5 & 2,5 & 3,0 & 2,0 & 1,8 & 2,0 & 4,2 & 2,0 \\ 3,0 & 2,5 & 2,5 & 3,0 & 2,5 & 2,5 & 2,0 & 4,0 & 2,0 \\ & & & & & & & & \\ 1,5 & 0,9 & 1,4 & 0,9 & 0,8 & 0,5 & 0,9 & 1,6 & 1,3 \\ 1,0 & 1,0 & 0,7 & 1,0 & 1,0 & 1,0 & 1,2 & 1,5 & 1,0 \\ 318 & 333 & 338 & 350 & 338 & 361 & 340 & 286 & 284\end{array}$

Inflation Target

$\begin{array}{lllllllllll}\text { Middle band } & 3,0 & 2,5 & 2,5 & 2,5 & 2,5 & 2,5 & 2,0 & 2,0 & 2,0 & 2,0 \\ \text { Upper band } & 3,5 & 3,5 & 3,5 & 3,5 & 3,5 & 3,5 & 3,0 & 3,0 & 3,0 & 3,0 \\ \text { Lower band } & 2,5 & 1,5 & 1,5 & 1,5 & 1,5 & 1,5 & 1,0 & 1,0 & 1,0 & 1,0\end{array}$

1/ Percent variation in the Index December this year with respect to December last year.

Note: Expectations are 12-months-ahead forecast from survey data. 
Table 2

Inflation and Inflation Expectations Statistics

\section{CPI Inflation Core Inflation}

Panel A: Correlation coefficient

$\begin{array}{lll}\text { Financial Institutions } & 86 \% & 87 \% \\ \text { Firms } & 73 \% & 71 \%\end{array}$

Panel B: Mean squared error

Financial Institutions

Mean $\quad 4,40 \quad 2,20$

$\begin{array}{lll}\text { Median } & 4,18 & 1,98\end{array}$

Firms

$\begin{array}{lll}\text { Mean } & 5,49 & 3,32\end{array}$

$\begin{array}{lll}\text { Median } & 3,97 & 3,09\end{array}$

Table 3

Granger Causality Test: FMs and Financial Institutions

Prob.

Financial Institutions do not Granger cause firms' expectations 0.02

Firms do not Granger cause financial institutions' expectations $\quad 0.82$

Table 4

Estimating and Testing for Information Rigidity

$M_{t}\left[\pi_{t, t+4}\right]=\alpha_{0}+\alpha_{1} S_{t}\left[\pi_{t, t+4}\right]+\alpha_{2} M_{t-1}\left[\pi_{t-1, t+3}\right]+\alpha_{3} \pi_{t}+\alpha_{4} F E_{t}\left[\pi_{t-4, t}\right]+\varepsilon_{t}$

\begin{tabular}{|c|c|c|c|c|c|c|c|c|}
\hline Equation & $\alpha_{0}$ & $\alpha_{1}$ & $\alpha_{2}$ & $\alpha_{3}$ & $\alpha_{4}$ & $\check{R}^{2}$ & Test & $\rho$-value \\
\hline \multirow[t]{2}{*}{1} & 2,60 & & & & & 0,00 & $\alpha_{0}=0$ & 0,00 \\
\hline & $0,21^{* * *}$ & & & & & & & \\
\hline \multirow[t]{2}{*}{2} & & 0,46 & 0,51 & & & 0,85 & $\alpha_{1}+\alpha_{2}=1$ & 0,28 \\
\hline & & $0,12^{* \star *}$ & $0,11^{* * *}$ & & & & & \\
\hline \multirow[t]{2}{*}{3} & $-0,36$ & 0,64 & 0,50 & & & 0,83 & & \\
\hline & 0,24 & $0,15^{* * *}$ & $0,13^{* * *}$ & & & & & \\
\hline \multirow[t]{2}{*}{4} & & 0,88 & & 0,11 & & 0,69 & & \\
\hline & & $0,08^{* * *}$ & & 0,07 & & & & \\
\hline \multirow[t]{2}{*}{5} & & 0,97 & & & $-0,05$ & 0,68 & & \\
\hline & & $0,06^{* * *}$ & & & 0,06 & & & \\
\hline \multirow[t]{2}{*}{6} & & 0,40 & 0,49 & 0,08 & & 0,86 & & \\
\hline & & $0,13^{* * *}$ & $0,11^{* * *}$ & 0,04 * & & & & \\
\hline \multirow[t]{2}{*}{7} & & 0,45 & 0,52 & & 0,03 & 0,85 & & \\
\hline & & $0,14^{* * *}$ & $0,14^{* \star *}$ & & 0,05 & & & \\
\hline \multirow[t]{2}{*}{8} & & & 0,77 & 0,18 & & 0,78 & & \\
\hline & & & $0,06^{* * *}$ & $0,05^{* * *}$ & & & & \\
\hline \multirow[t]{2}{*}{9} & & & 0,95 & & 0,08 & 0,73 & & \\
\hline & & & $0,03^{* * *}$ & & 0,04 * & & & \\
\hline
\end{tabular}

Newey-West HAC Standard Errors \& Covariance error correction.

One, two, and three stars indicate, respectively, statistical significance at the the 10,5 , and 1 percent level. 
Table 5

Estimating and Testing for Information Rigidity: Industry level

$M_{t}\left[\pi_{t, t+4}\right]=\alpha_{1} S_{t}\left[\pi_{t, t+4}\right]+\alpha_{2} M_{t-1}\left[\pi_{t-1, t+3}\right]+\varepsilon_{t}$

\begin{tabular}{|c|c|c|c|c|}
\hline \multirow[t]{2}{*}{ Equation } & \multirow[t]{2}{*}{$\alpha_{1}$} & \multirow[t]{2}{*}{$\alpha_{2}$} & \multirow[t]{2}{*}{$\check{\mathrm{R}}^{2}$} & Test: $\quad \alpha_{1}+\alpha_{2}=1$ \\
\hline & & & & $\rho$-value \\
\hline \multirow[t]{2}{*}{ Agriculture, Fishing and Mining } & 0,53 & 0,46 & 0,85 & 0,84 \\
\hline & $0,10^{* * *}$ & $0,09 * * *$ & & \\
\hline \multirow[t]{2}{*}{ Manufacturing } & 0,59 & 0,41 & 0,81 & 0,80 \\
\hline & $0,12^{* * *}$ & $0,11^{* * *}$ & & \\
\hline \multirow[t]{2}{*}{ Trade } & 0,38 & 0,60 & 0,82 & 0,42 \\
\hline & $0,09 * * *$ & $0,08 * * *$ & & \\
\hline \multirow[t]{2}{*}{ Construction } & 0,37 & 0,61 & 0,74 & 0,70 \\
\hline & $0,13 * * *$ & $0,11 * * *$ & & \\
\hline \multirow[t]{2}{*}{ Energy } & 0,51 & 0,48 & 0,89 & 0,33 \\
\hline & $0,07^{* * *}$ & $0,07^{* * *}$ & & \\
\hline \multirow[t]{2}{*}{ Services } & 0,48 & 0,49 & 0,84 & 0,33 \\
\hline & $0,11^{* * *}$ & 0,10 *** & & \\
\hline
\end{tabular}

Newey-West HAC Standard Errors \& Covariance error correction.

One, two, and three stars indicate, respectively, statistical significance at the the 10,5 , and 1 percent level.

Table 6

Estimating and Testing for Information Rigidity: Firm level

$M_{i t}\left[\pi_{t, t+1}\right]=\alpha_{0}+\alpha_{1} S_{t}\left[\pi_{t, t+1}\right]+\alpha_{2} M_{i t-1}\left[\pi_{t-1, t}\right]+\varepsilon_{i t}$

\begin{tabular}{|c|c|c|c|c|c|c|c|c|}
\hline & $(1)$ & & (2) & & (3) & & $(4)$ & \\
\hline \multirow[t]{2}{*}{$\alpha_{0}$} & & & -0.10 & & -0.16 & & -0.10 & \\
\hline & & & 0.06 & * & 0.06 & * & 0.06 & \\
\hline \multirow[t]{2}{*}{$\alpha_{1}$} & 0.63 & & 0.73 & & 0.68 & & 0.72 & \\
\hline & 0.01 & $* * *$ & 0.02 & $* * *$ & 0.02 & $* * *$ & 0.02 & $* * *$ \\
\hline \multirow[t]{2}{*}{$\alpha_{2}$} & 0.42 & & 0.36 & & 0.42 & & 0.36 & \\
\hline & 0.01 & $* \star \star$ & 0.01 & $* * *$ & 0.01 & $* * *$ & 0.01 & $* \star *$ \\
\hline$\check{\mathrm{R}}^{2}$ & 0.35 & & 0.36 & & 0.35 & & 0.36 & \\
\hline Cross section fixed effect & No & & Yes & & No & & Yes & \\
\hline Period fixed effect & No & & No & & Yes & & Yes & \\
\hline
\end{tabular}


Table 1A

Annual Rate of Inflation in the Peruvian Economy

\begin{tabular}{lrr}
\hline \hline & $\mathbf{1 9 5 0 - \mathbf { 2 0 1 0 }}$ & $\mathbf{2 0 0 1} \mathbf{- 2 0 1 0}$ \\
\hline Average & 224,74 & 2,29 \\
Median & 8,89 & 1,80 \\
Mode & 3,73 & \\
& & \\
SD & 1050,62 & 1,99 \\
Interquartil range & 42,28 & 2,34 \\
Max & & \\
Min & 649,65 & 6,65 \\
Max (year) & $-0,13$ & $-0,13$ \\
Min (year) & 1990 & 2008 \\
Number of years & 2001 & 2001 \\
& & \\
\end{tabular}


FIGURE 1 - DisTRIBUTION OF FMs' EXPECTATIONS ON INFLATION
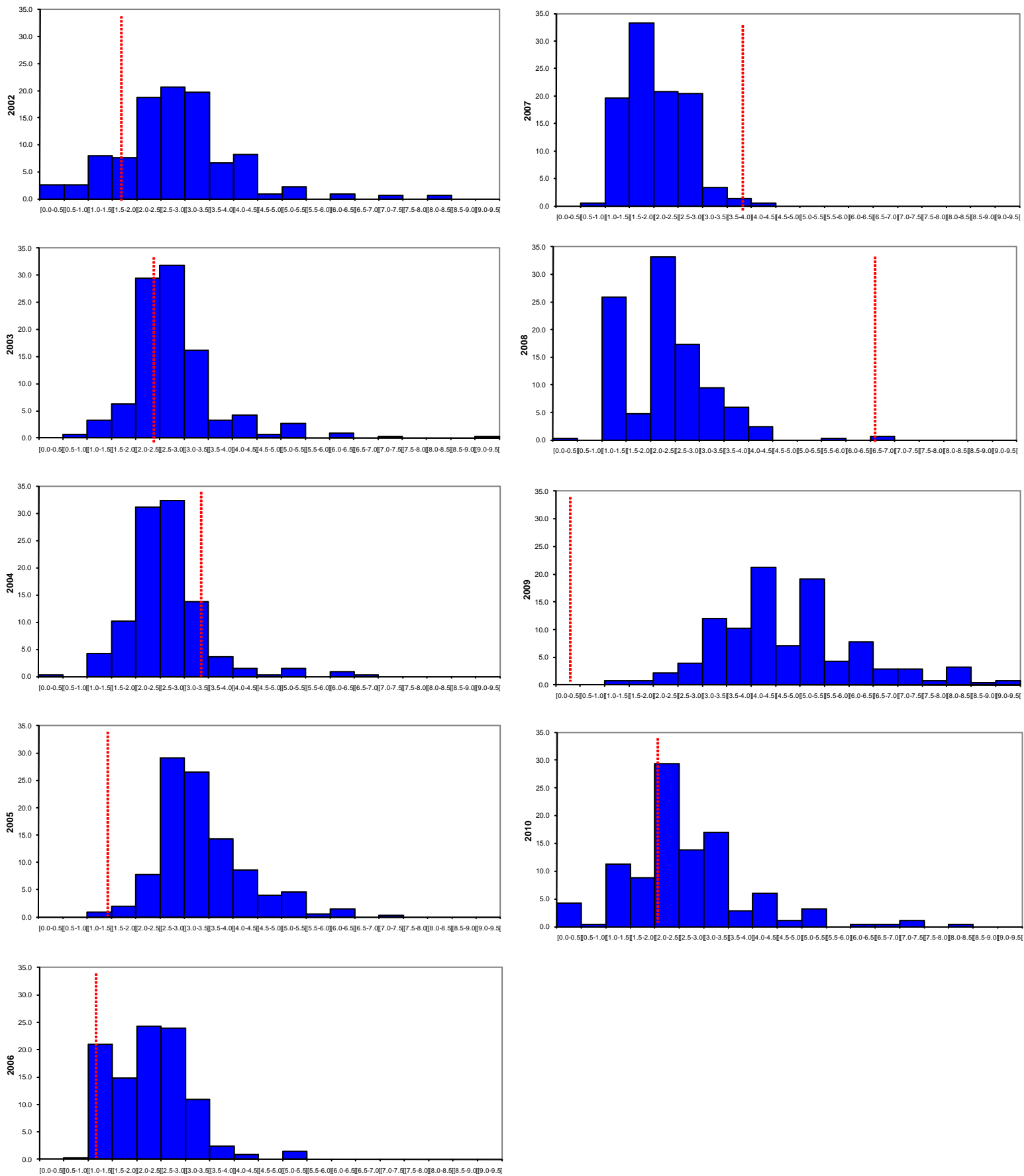

NOTE: FMS' EXPECTATIONS ARE 12-MONTHS-AHEAD FORECAST OF INFLATION, TAKEN ON DECEMBER OF EACH YEAR. THE DARK LINE IS THE REALIZATION OF CPI INFLATION. 
FIGURE 2 - DISTRIBUTION OF FINANCIAL INSTITUTIONS' EXPECTATIONS ON INFLATION
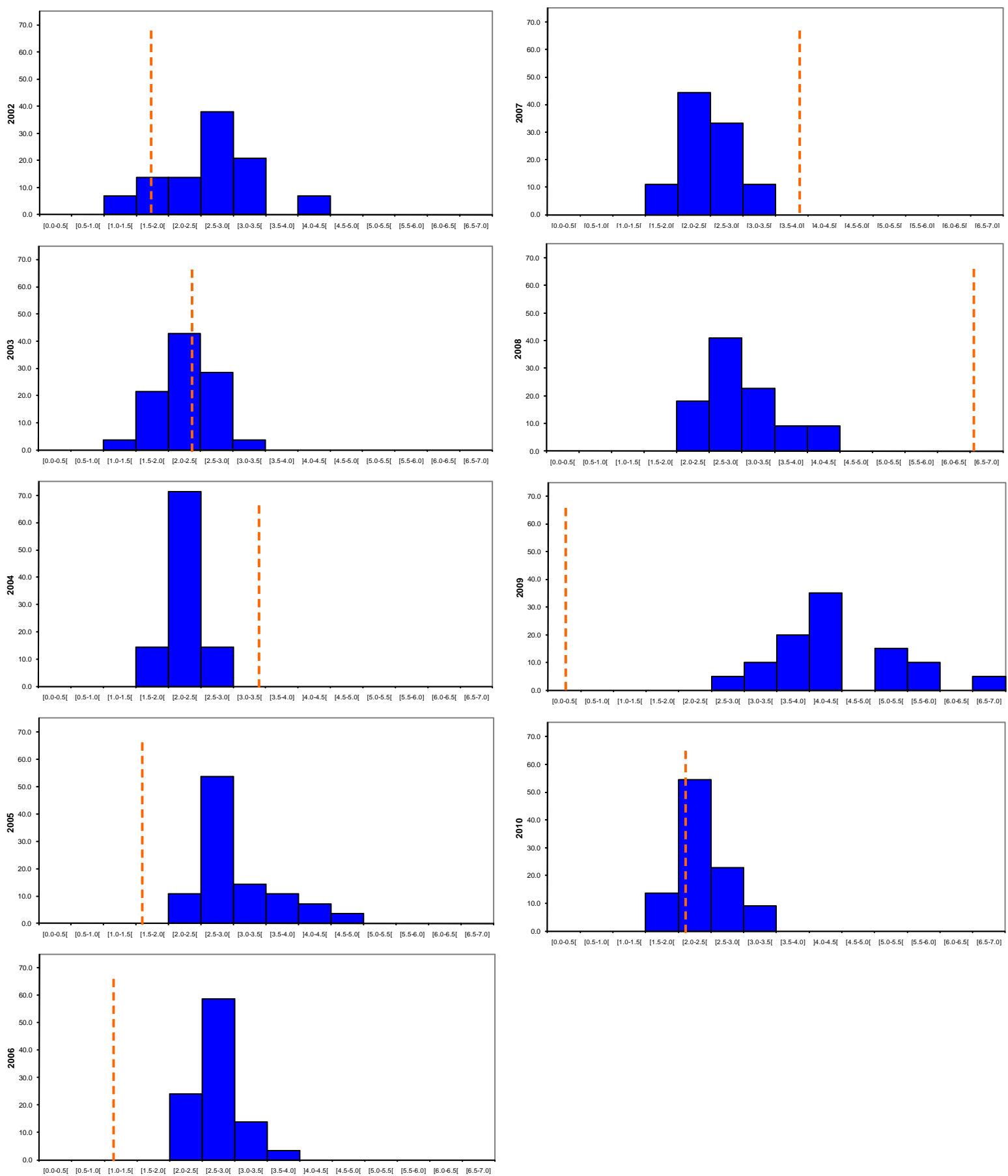

NOTE: FINANCIAL INSTITUTIONS' EXPECTATIONS ARE 12-MONTHS-AHEAD FORECAST OF INFLATION, TAKEN ON DECEMBER OF EACH YEAR. THE DARK LINE IS THE REALIZATION OF CPI INFLATION. 
Figure 3 - Box Plot Of Inflation EXPECTATIONS

\section{A: FMs' EXPECTATIONS}

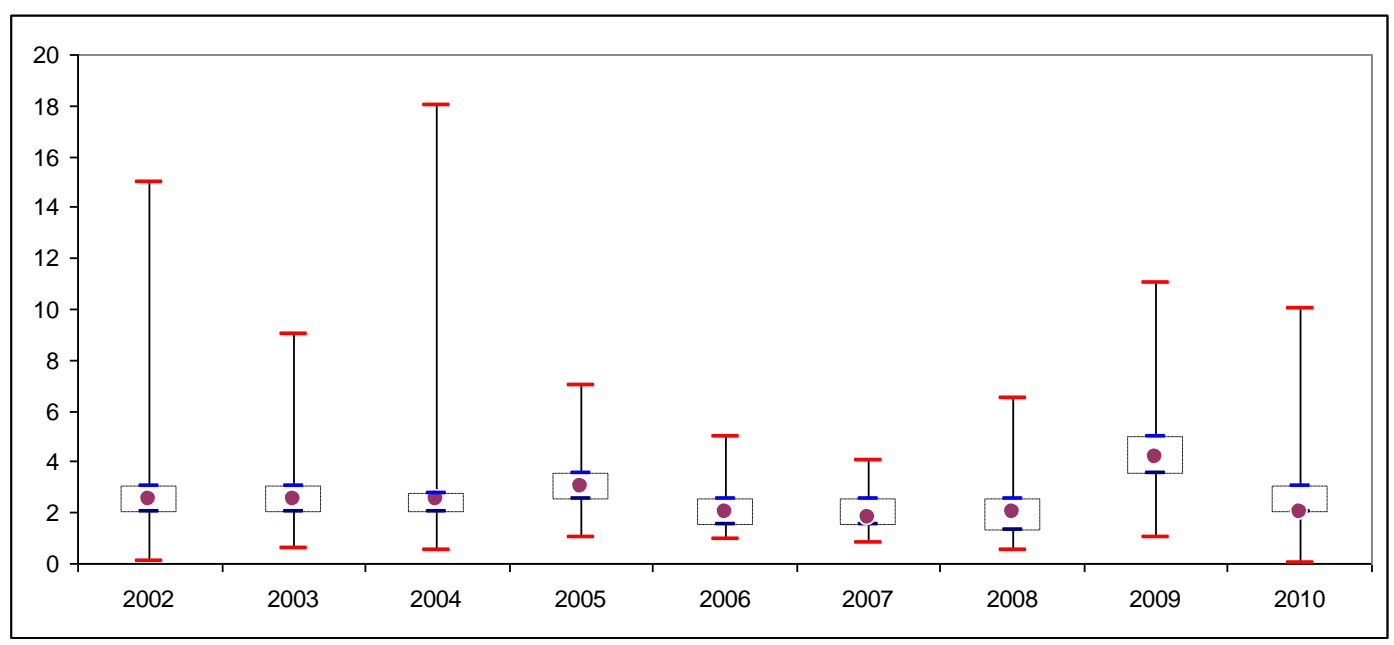

B: FINANCIAL INSTITUTIONS' EXPECTATIONS

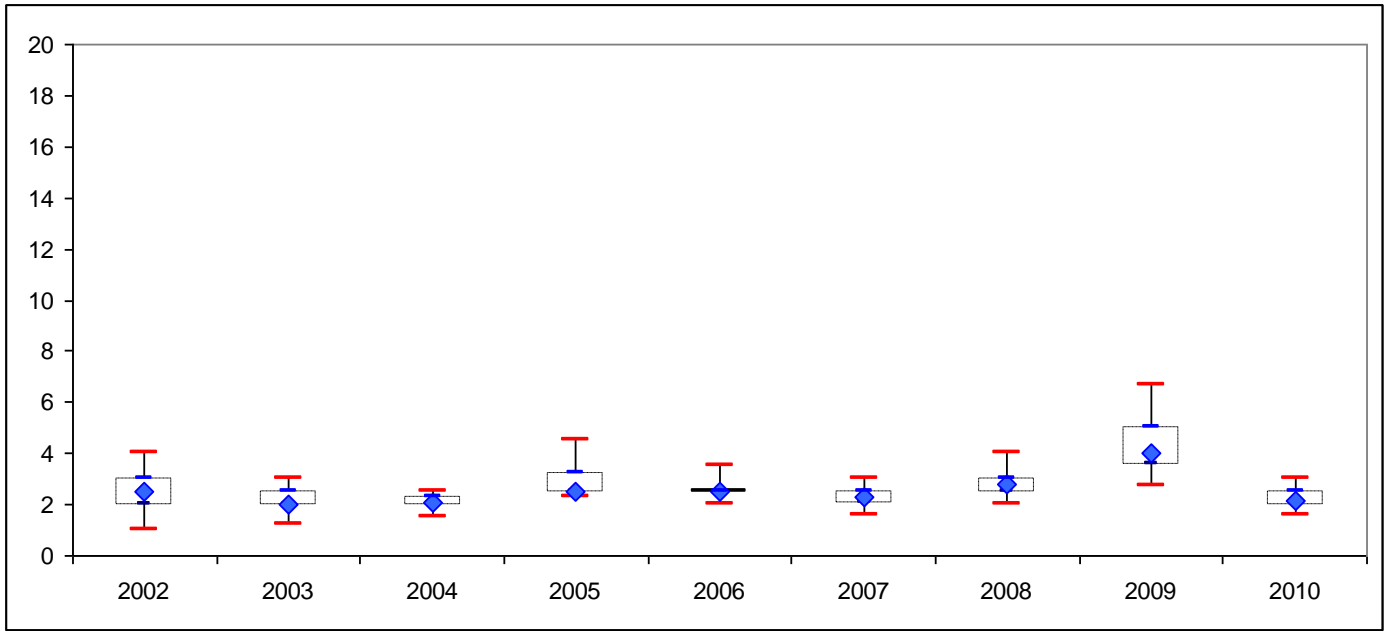


FIGURE 4 - INFORMATION STICKINESS AND EXPECTATIONS: INDUSTRY LEVEL

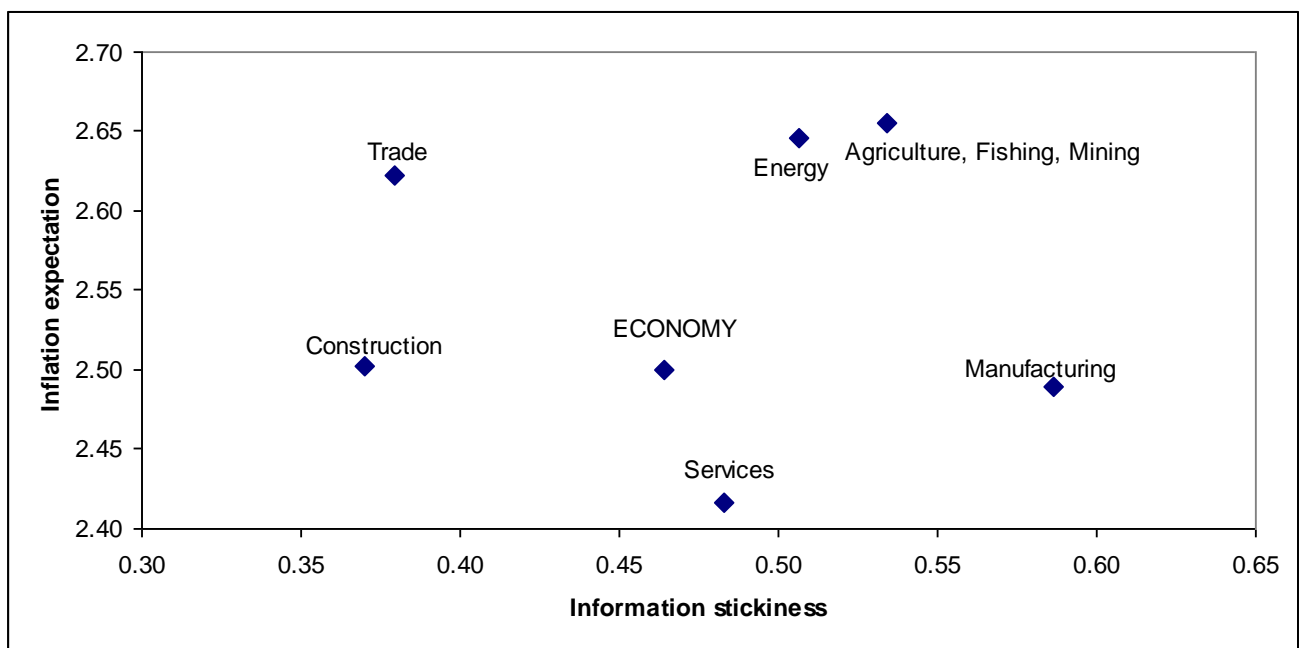

NOTE: INFLATION EXPECTATION IS THE AVERAGE OF THE 12-MONTH FORECAST MADE BY ALL FMS IN EVERY INDUSTRY.

FIGURE 5 - INFORMATION STICKINESS AND DISAGREEMENTS: INDUSTRY LEVEL

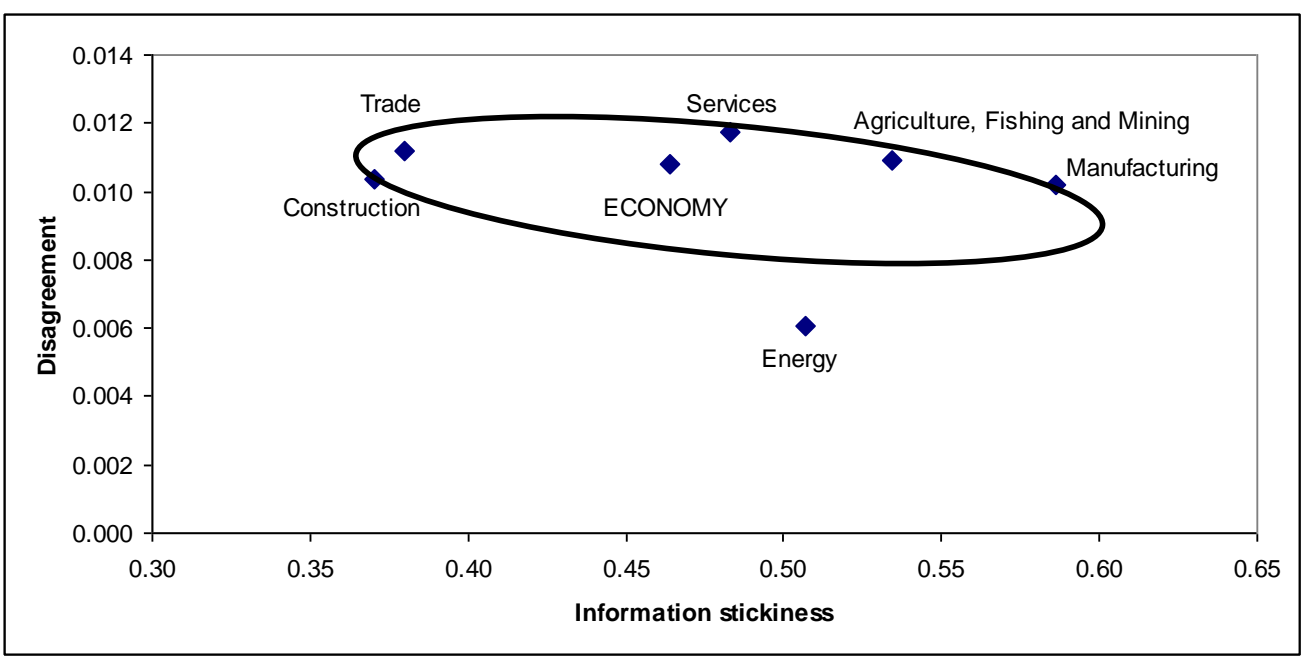

NOTE: DiSAGREEMENT IS THE STANDARD DEVIATION OF THE 12-MONTH FORECAST MADE BY ALL FMS IN EVERY INDUSTRY. 
FIGURE 6 - INFORMATION STICKINESS AND MARKUP: INDUSTRY LEVEL

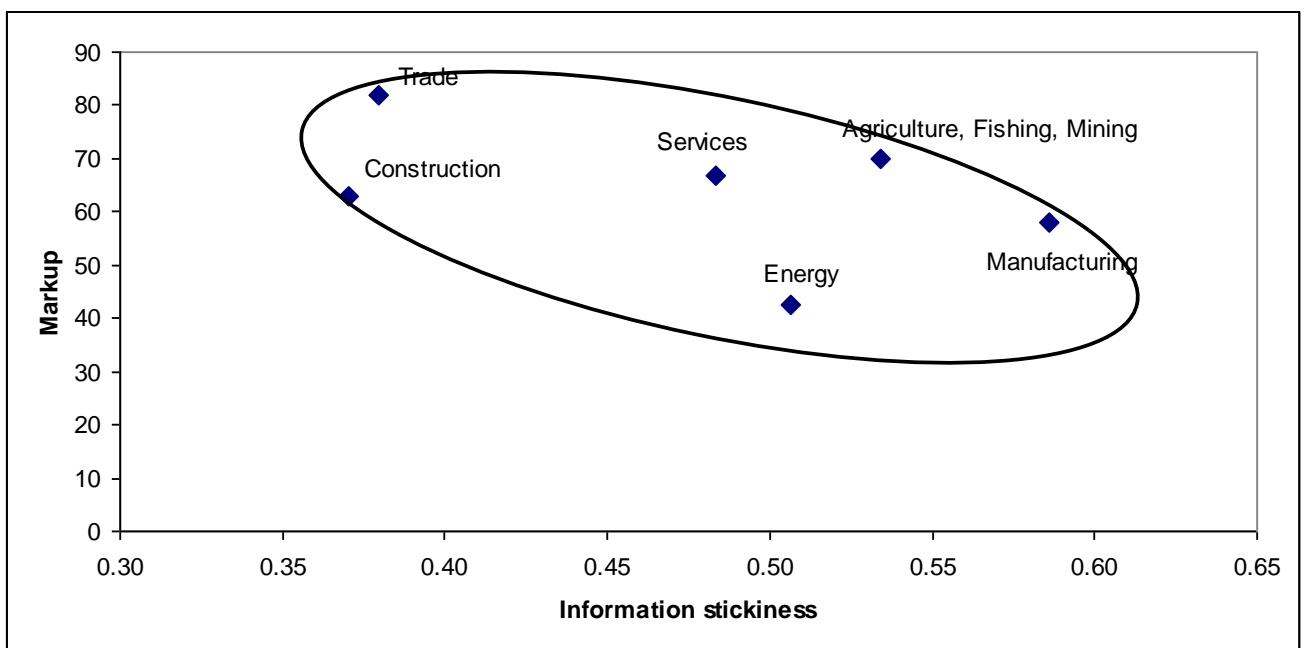

Note: MARKuP IS THE RATIO BETWEen THE EXCESS IN PROFITS RELATIVE TO THE AGGREGATE VALUE GENERATED PER ECONOMIC ACTIVITY FROM THE LAST INPUT-OUTPUT TABLE FOR THE PERUVIAN ECONOMY. 
FIGURE 1A - INFLATION EXPECTATIONS AND INFLATION TARGETING

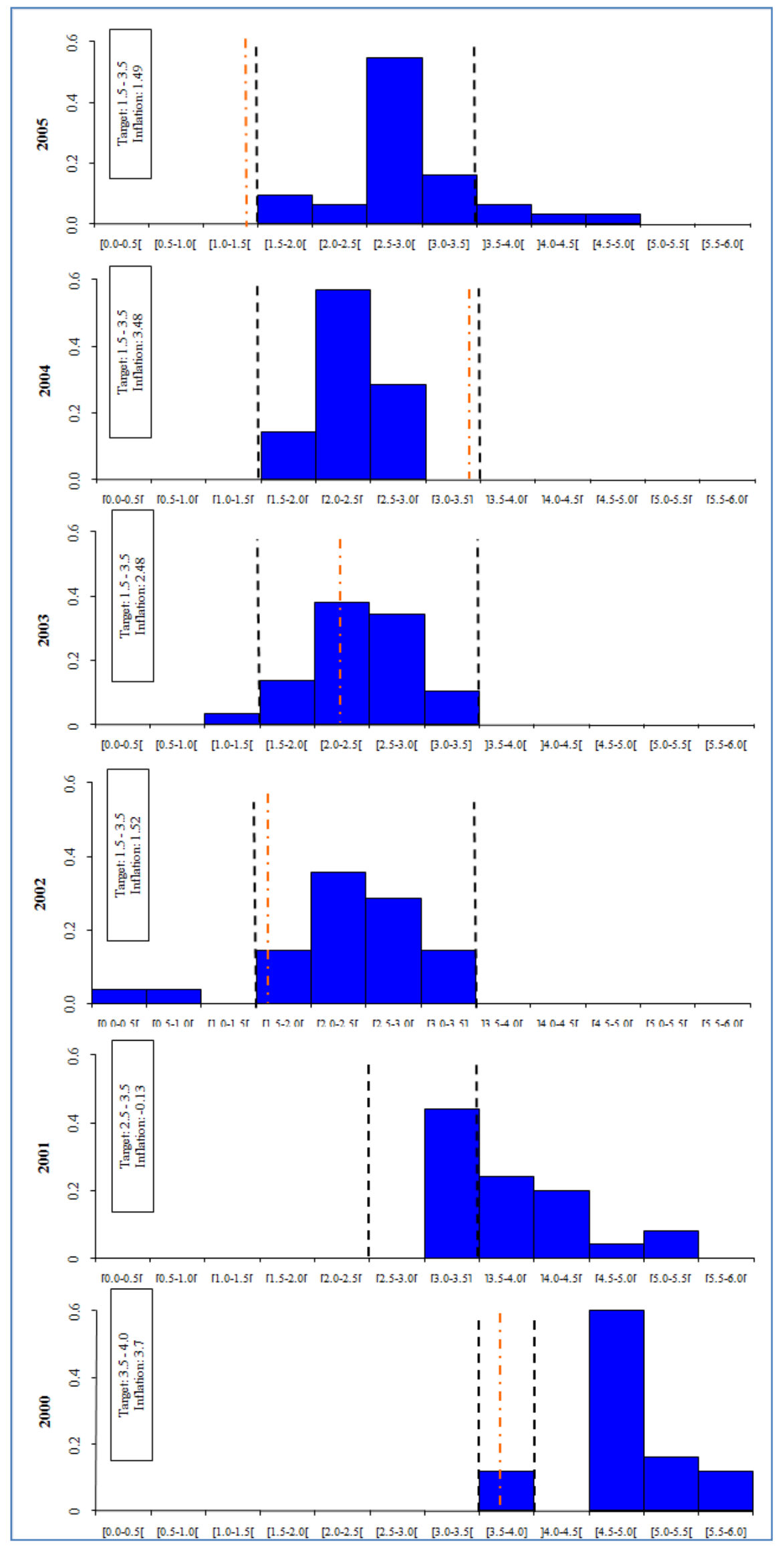




\section{FIGURE 1A - INFLATION EXPECTATIONS AND INFLATION TARGETING (CONTINUE)}

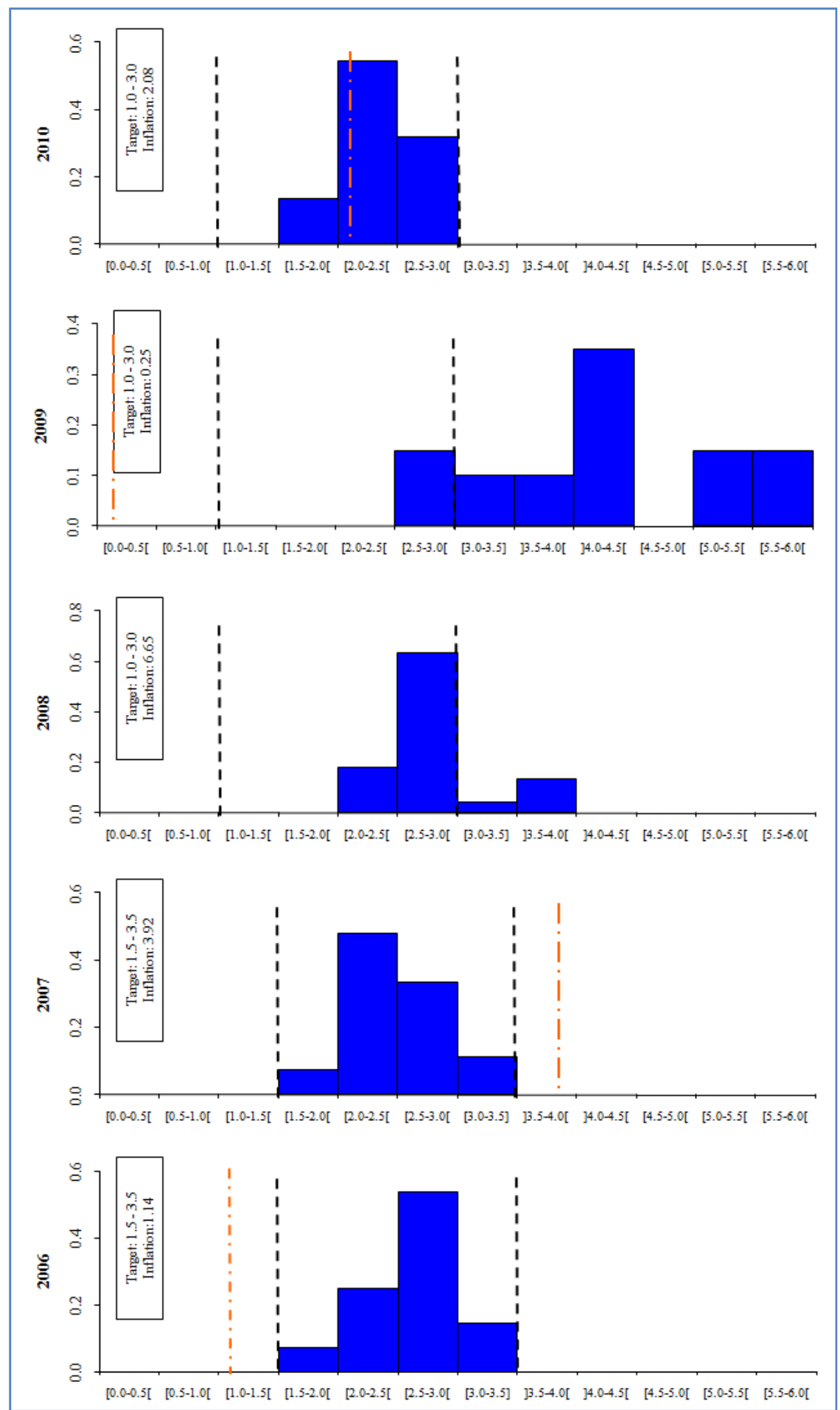

NOTE: EXPECTATIONS ARE 12-MONTHS-AHEAD FORECAST OF INFLATION FROM FINANCIAL INSTITUTIONS, TAKEN ON DECEMBER OF EACH YEAR. THE DARK LINES ARE THE INFLATION TARGETING BAND. THE LIGHT LINE IS THE REALIZATION OF CPI INFLATION. VALUES OF INFLATION FOR 2001 AND 2008 ARE NOT GRHAPED BECAUSE THEY ARE OUTSIDE THE RANGE OF THE HISTOGRAM. THE INTERVALS ARE ADJUSTED EACH TIME THE CENTRAL BANK CHANGED THE INFLATION TARGET SO EACH INTERVAL CONSIDERS RESPONSES THAT ARE CONSISTENT WITH THE BAND ANNOUNCED FOR THE CENTRAL BANK. 